\author{
Hideaki Obata MD, \\ Shigeru Saito MD PhD, \\ Nao Fujita $M D$, * \\ Yoshiaki Fuse MD, $\dagger$ \\ Keiji Ishizaki MD, \\ Fumio Goto MD PhD
}

\section{Epidural block with mepivacaine before surgery reduces long- term post-thoracotomy pain}

Purpose: To examine the effect of continuous epidural block initiated before thoracic surgery upon early and long-term postoperative pain.

Methods: In a double-blind study, 70 patients scheduled for thoracic surgery under general anesthesia were assigned randomly to receive continuous epidural block with mepivacaine $1.5 \%$ initiated either $20 \mathrm{~min}$ before surgical incision (Pre group) or at completion of surgery (Post group). In both groups the initial dose was $4 \mathrm{ml}$, followed by a continuous infusion at $4 \mathrm{ml} \cdot \mathrm{hr}^{-1}$ until $72 \mathrm{hr}$ after operation. Indomethacin suppositories, $50 \mathrm{mg}$, were administered on request as supplementary analgesics. Visual analogue scale at rest was assessed four hours after operation, and then every $24 \mathrm{hr}$ after operation on postoperative days I through 7, and also days 14 and 30 . At three and six months after operation, all patients were interviewed by telephone with respect to postoperative pain. The most severe pain was assessed using modified numerical rating scale.

Results: By a visual analogue scale, postoperative pain was less in the Pre group than in the Post group at four hours, two and three days after operation $(P<0.05)$. By a numerical rating scale six months after operation, pain was less in the Pre group than in the Post group $(P=0.015)$. The percentage of pain-free patients was higher in the Pre group than in the Post group at three $(P=0.035)$ and six $(P=0.0086)$ months after operation.

Conclusion: Continuous epidural block initiated prior to surgery may reduce long-term post-thoracotomy pain.

Objectif : Examiner l'effet d'un blocage épidural continu, amorcé avant une intervention chirurgicale thoracique, sur la douleur postopératoire précoce et de long terme.

Méthode : L'étude à double insu a porté sur 70 patients qui devaient subir une opération thoracique sous anesthésie générale. Répartis au hasard, ils ont reçu un blocage épidural continu avec de la mépivacaïne à $1,5 \%$, administrée soit 20 min avant l'incision chirurgicale (groupe Pré), soit à la fin de l'intervention (groupe Post). Pour tous, la dose initiale a été de $4 \mathrm{ml}$ suivie d'une perfusion continue à $4 \mathrm{ml} \cdot \mathrm{h}^{-1}$ jusqu'à $72 \mathrm{~h}$ après l'opération. Des suppositoires de $50 \mathrm{mg}$ d'indométhacine ont été administrés sur demande pour compléter l'analgésie. La douleur a été évaluée au repos selon l'échelle visuelle analogique, $4 \mathrm{~h}$ après l'opération et puis à toutes les $24 \mathrm{~h}$ des jours I à 7 et aussi les jours 14 et 30 . Trois mois et six mois après l'opération, tous les patients ont été interrogés par téléphone au sujet de la douleur postopératoire. La douleur la plus sévère a été évaluée en utilisant une échelle d'estimation numérique modifiée.

Résultats : Selon l'échelle visuelle analogique, la douleur postopératoire était plus faible chez les patients du groupe Pré que chez ceux du groupe Post à $4 h$, deux et trois jours après l'opération $(P<0,05)$. Selon une échelle d'estimation numérique, la douleur était moins intense chez les patients du groupe Pré que chez ceux du groupe Post $(P=0,015)$ six mois après l'opération. Le pourcentage de patients sans douleur était plus élevé dans le groupe Pré que dans le groupe Post à trois mois $(P=0,035)$ et à six mois $(P=0,0086)$ après l'opération.

Conclusion : Le blocage épidural continu amorcé avant l'intervention chirurgicale peut réduire la douleur qui se prolonge après une thoracotomie.

From the Department of Anesthesiology and Reanimatology, Gunma University, School of Medicine, the Department of Anesthesia, Saitama Cardiovascular and Respiratory Center, ${ }^{*}$ and the Department of Anesthesia, Saitama Cancer Center, $\dagger$ Japan.

Address correspondence to: Dr. Hideaki Obata, Department of Anesthesiology and Reanimatology, Gunma University, School of Medicine. 3-39-22, Showa-machi, Maebashi, Gunma, 371-8511, Japan. Phone: 81-27-220-8453; Fax: 81-27-220-8473.

Accepted for publication August 22, 1999 
$\mathrm{P}$ ERIPHERAL tissue injury and afferent Cfibre stimuli provoke an activity dependent increase in excitability of dorsal horn neurons termed central sensitization. ${ }^{1,2}$ Evidence from basic research indicates that administration of analgesic drugs is more effective if given before, rather than after, a noxious stimulus. ${ }^{3,4}$ Some clinical studies have upheld this notion by demonstrating benefits of pre-emptive analgesia with local anesthetics, opioids, nonsteroidal anti-inflammatory drugs (NSAIDs), or combined techniques. ${ }^{5,6}$ However, the clinical usefulness of pre-emptive analgesia remains controversial.?

Post-thoracotomy pain is considered to be particularly severe and is likely to last for several years after surgery. ${ }^{8}$ Although many reports have described methods to control early post-thoracotomy pain, we are not aware of prospective study attempts to reduce this longlasting pain. Since Katz et al. demonstrated that the intensity of early postoperative pain correlates with that of long-term post-thoracotomy pain, ${ }^{9}$ we hypothesized that reducing early post-thoracotomy pain with preemptive analgesia would result in a lower incidence of and a lower intensity of long-term post-thoracotomy pain. Continuous epidural block is a useful strategy for such pre-emptive analgesia, and is the technique often used to provide post-thoracotomy analgesia. ${ }^{10,11}$ The aim of this study was to determine whether continuous epidural block initiated before the surgical incision had a beneficial effect on early and long-term postoperative pain in patients undergoing thoracotomy.

\section{Patients and Methods}

After obtaining approval from the ethics committee at our institution and informed consent from the subjects, we studied 70 patients undergoing unilateral posterolateral thoracotomy for intrathoracic surgery. No patient had complications likely to affect their general physical condition. Exclusion criteria were a history of chronic pain or regular use of analgesics, contraindications to use of NSAIDs, contraindications to the insertion of an epidural catheter, a history of surgery with malignancy within five years, heart disease, and psychiatric disease. All patients were instructed in the use of a $10-\mathrm{cm}$ visual analogue scale (VAS) from $0 \mathrm{~cm}$ (no pain) to $10 \mathrm{~cm}$ (worst pain imaginable).

\section{Epidural catheter}

On the day before operation all patients underwent insertion of a 17-gauge epidural catheter (Minikit, Abott Ireland, Sligo, Ireland) via the $T_{5-6}$ intervertebral space. The catheter was advanced $5 \mathrm{~cm}$ in a cephalad direction. The position of the catheter tip was tested using $4 \mathrm{ml}$ lidocaine $1 \%$ containing
$1 ; 100,000$ epinephrine to exclude subarachnoid or intravascular placement. The sensory block level was confirmed $20 \mathrm{~min}$ after the test dose injection using pinprick. During the continuous epidural block, the level of block was assessed every day and at the end of continuous epidural block, the location of the catheter tip was verified by epidurography.

\section{Anesthetic management}

On the day of operation, all patients were premedicated with 3 - $5 \mathrm{mg}$ midazolam im one hour before operation. General anesthesia was induced with $4-5$ $\mathrm{mg} \cdot \mathrm{kg}^{-1}$ thiopental and $0.1 \mathrm{mg} \cdot \mathrm{kg}^{-1}$ vecuronium to facilitate tracheal intubation with a double-lumen tracheal tube. Anesthesia was maintained with isoflurane 0 - $4 \%$ inspired and nitrous oxide in oxygen. Muscular relaxation was achieved by intermittent injection of vecuronium. For abnormal hypertension (systolic blood pressure $>180 \mathrm{mmHg}$ ) nicardipine hydrochloride $i v$, a calcium channel blocker, was infused, and for abnormal hypotension (systolic blood pressure $<80 \mathrm{mmHg}$ ) fluid therapy or $5 \mathrm{mg}$ ephedrine $i v$ was used.

After induction of anesthesia, the patients were allocated randomly to one of two groups. The patients were not aware of the group to which they had been assigned. In the Pre group, $4 \mathrm{ml}$ mepivacaine $1.5 \%$ were administered epidurally 20 min before the surgical incision, followed by a continuous infusion at $4 \mathrm{ml} \cdot \mathrm{hr}^{-1}$, until $72 \mathrm{hr}$ after operation. For the Post group the procedure was the same except that the first $4 \mathrm{ml}$ dose was administered at completion of the operation. Immediately after operation, patients were transferred to the intensive care unit and their tracheas were extubated after reversal of residual neuromuscular block with neostigmine and atropine. Anesthesia for these patients was administered by several anesthesiologists.

\section{Postoperative pain management and assessment}

After operation, all patients were observed by nursing staff unaware of Pre- and Post- group assignment. If pain relief was inadequate $50 \mathrm{mg}$ indomethacin $p r$ were administered on request and each patient's use of indomethacin for each 24-hr period was recorded. No other analgesics (including opioids) were administered. The VAS at rest was assessed four hours after operation, and then every $24 \mathrm{hr}$ on postoperative days 1 through 7 , and also days 14 and 30 . At three and six months after operation, all patients were interviewed by telephone with respect to postoperative pain in terms of a pain questionnaire that they had been given on discharge (Appendix). The most severe pain was assessed using a modified numerical rating scale (NRS). Postoperative pain was assessed by an anesthesiologist 
unaware of the patient's group assignment. Patients who had recurrence of malignancy within 12 mo after operation were excluded from the data analysis.

\section{Statistical analysis}

The number of patients in each group was determined based on post-thoracotomy pain variance taken from a previous study using similar methodology. ${ }^{12}$ In order to detect a difference of $1.5 \mathrm{~cm}$ between groups in the VAS as clinically significant with a power of 0.8 and a significance level of 0.05 , at least 27 patients were required in each group. We assessed the VAS and postoperative indomethacin dose over the time between the groups by two-way analysis of variance for repeated measurements. In addition, one-way analysis of variance and Scheffe's test were performed to compare the values at each measurement points. We compared the NRS obtained three and six months after surgery using the Mann-Whitney $U$ test. We used chi-square analysis to compare the percentage of each pain condition at three and six months after surgery. We evaluated other outcomes using unpaired Student's $t$ tests or Fisher's exact test as appropriate. A $P$ value $<0.05$ was considered statistically significant.

\section{Results}

Twelve patients were eliminated from the study, because of accidental dislodgment of the epidural catheter (two patients), loss to follow-up after discharge (five patients), death within six months of surgery (three patients), or recurrence of malignant tumour within 12 mo of surgery (two patients). The study protocol was completed by 28 patients in the Pre group and 30 patients in the Post group. The intraoperative dose of isoflurane was lower in the Pre group $(P<0.01$, Table I). No differences were evident between groups for surgical procedure or pathological diagnosis (Table II). The VAS scores at rest were lower in the Pre group at four hours after operation and on two and three postoperative days $(P<0.05$, Figure 1$)$. The groups did not differ in the use of postoperative indomethacin suppositories until postoperative day 7 (Figure 2). The NRS, six months after operation, was lower in the Pre group $(P=0.015$, Figure 3$)$. The percentages of pain-free patients were higher in the Pre group at three $(P=$ $0.035)$ and six months $(P=0.0086)$ after operation (Table III). There were no differences in other outcomes including intraoperative nicardipine or ephedrine doses (data not shown).

\section{Discussion}

In the present study, we found differences in pain scores in the early and late postoperative periods,
TABLE I Patient profiles and clinical variables.

\begin{tabular}{lll}
\hline & $\begin{array}{l}\text { Pre grout } \\
(n=28)\end{array}$ & $\begin{array}{l}\text { Post group } \\
(n=30)\end{array}$ \\
\hline Age & $60.1 \pm 11.0$ & $65.1 \pm 9.8$ \\
Sex $(\mathrm{M} / \mathrm{F})$ & $20 / 8$ & $22 / 8$ \\
Height $(\mathrm{cm})$ & $161.3 \pm 7.8$ & $159.9 \pm 7.2$ \\
Weight $(\mathrm{kg})$ & $57.8 \pm 7.5$ & $56.3 \pm 8.1$ \\
Duration of surgery $(\mathrm{min})$ & $175.2 \pm 79.9$ & $168.8 \pm 64.9$ \\
Blood loss (ml) & $233.5 \pm 198.0$ & $240.5 \pm 222.7$ \\
Total isoflurane dose $(\mathrm{ml})$ & $40.5 \pm 19.2 *$ & $84.7 \pm 37.1$ \\
\hline
\end{tabular}

Data are represented as mean (SD).

${ }^{*} P<0.01$ compared with the Post group.

TABLE II Pathologic diagnoses and surgical procedures.

\begin{tabular}{lll}
\hline & $\begin{array}{l}\text { Pre group } \\
(n=28)\end{array}$ & $\begin{array}{l}\text { Post group } \\
(n=30)\end{array}$ \\
\hline Diagnosis & 22 & 26 \\
Malignant tumour & 22 & 20 \\
$\quad$ Bronchogenic carcinoma & 19 & 6 \\
$\quad$ Metastatic lung tumour & 3 & 1 \\
Benign tumour & 3 & 3 \\
Inflamatory disease & 3 & \\
Procedures & & 24 \\
Lobectomy & 20 & 5 \\
Wedge resection & 6 & 1 \\
Enucleation & 2 & \\
\hline
\end{tabular}

TABLE III Long-term post-thoracotomy pain

\begin{tabular}{llllll}
\hline & \multicolumn{2}{c}{3 months } & \multicolumn{3}{c}{6 months } \\
& Pre group & Post group & Pre group & Post grotsp \\
\hline Pain free (\%) & $50^{*}$ & 23 & $67 \dagger$ & 33 \\
Long-term pain (\%) & 50 & 77 & 33 & 67 \\
$\quad \begin{array}{l}\text { continuous } \\
\text { intermittent }\end{array}$ & 9 & 4 & 0 & 10 \\
$\begin{array}{l}\text { interfering with } \\
\text { life (\%) }\end{array}$ & 96 & 100 & 90 \\
$\begin{array}{l}\text { Taking medications } \\
\text { for pain (\%) }\end{array}$ & 11 & 0 & 0 & 0 & 3 \\
\hline
\end{tabular}

${ }^{*} P<0.05, \dagger P<0.01$ compared with the Post- group

between the patients with a continuos epidural block with mepivacaine initiated before and after thoracotomy. Moreover, we detected differences with respect to the percentage of pain-free patients at three and six months after operation.

Thoracotomy is among the most painful surgical procedures, and persistent chest wall pain is common. Kalso et al. reported that $44 \%$ of their patients had persistent post-thoracotomy pain lasting more than six months after hospital discharge. ${ }^{13}$ Matsunaga et al. reported that, among their patients, $67 \%$ complained of post-thoracotomy pain up to six months from oper- 


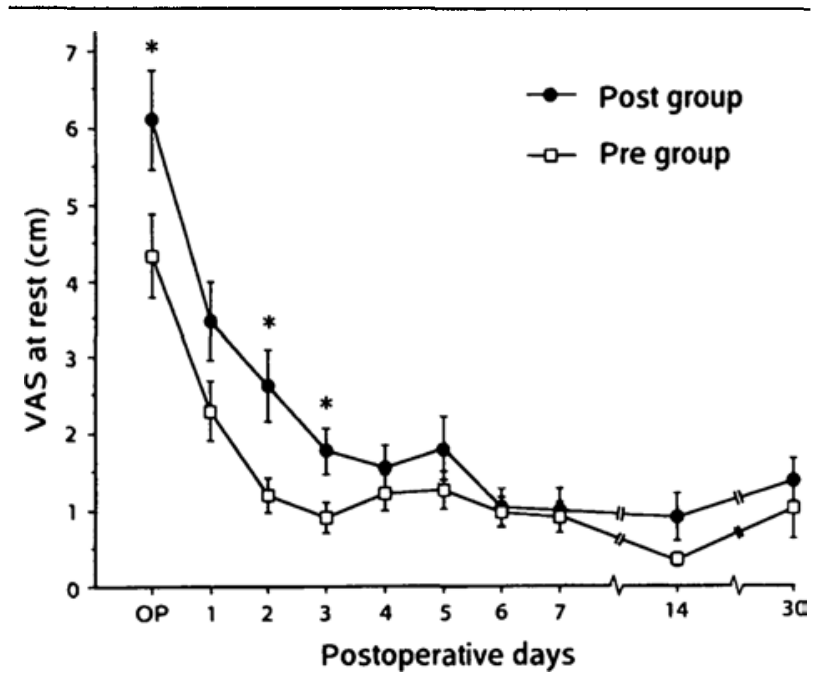

FIGURE 1 Visual analogue scale until $\mathbf{3 0}$ dy after surgery, in patients in whom continuous epidural block was initiated before surgery (Pre group) or after surgery (Post group). Mean \pm SEM. * $P<0.05$.

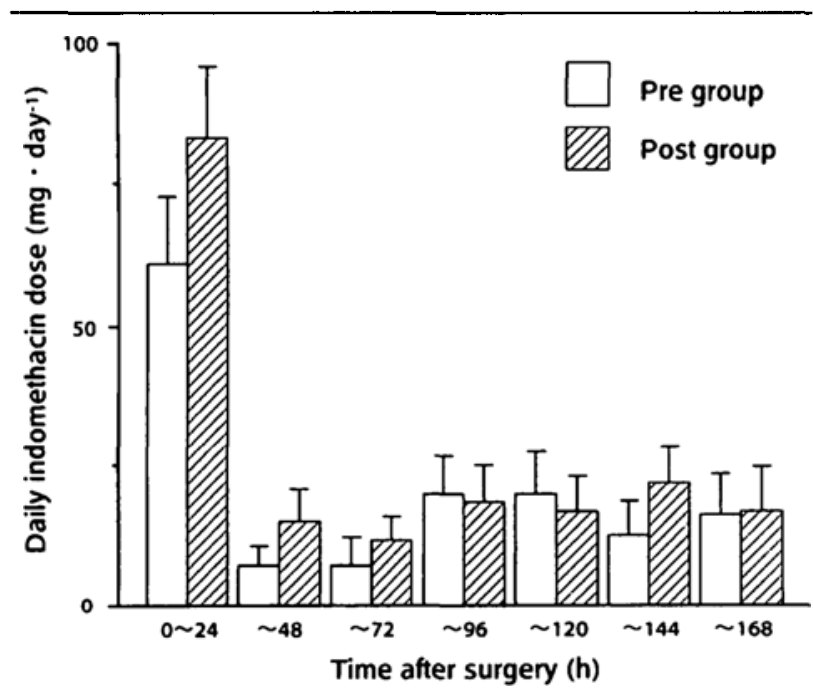

FIGURE 2 Daily indomethacin dose during each $24 \mathrm{hr}$ after operation until postoperative day seven. Mean \pm SEM.

ation, ${ }^{14}$ while Djaczman $e t a l$. noted that $55 \%$ of their patients had pain continuing for more than one year after thoracotomy. ${ }^{8}$ In the present study, the incidence of long-term post-thoracotomy pain in the Post group was consistent with the above experience. Post-thoracotomy pain reportedly shows neuropathic features, ${ }^{15,16}$ and the patients in the present study had

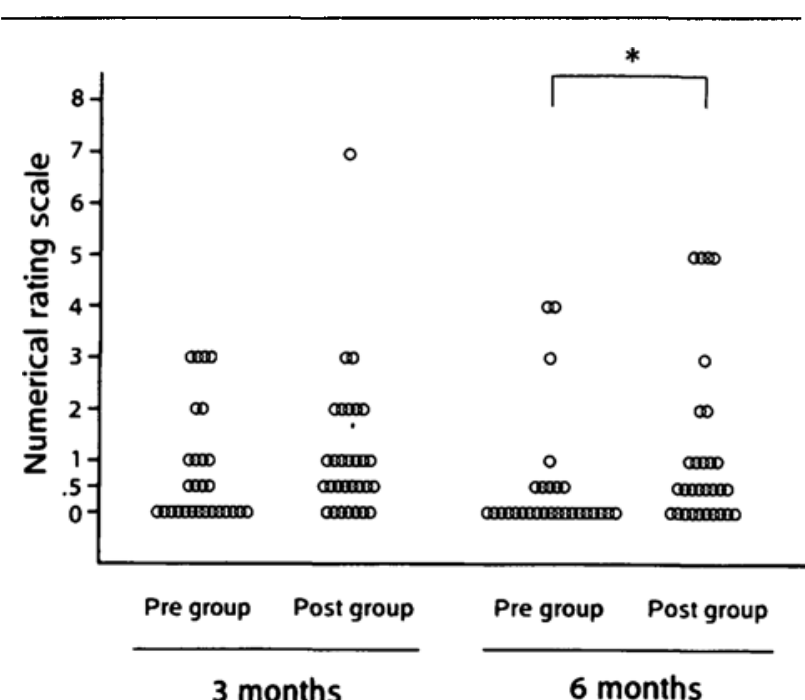

FIGURE 3 Numerical rating scale three and six months after operation. ${ }^{*} P<0.05$.

pain with such characteristics, including hypesthesia, numbness, tenderness, and a burning sensation (no quantitative statistical analysis were performed). Their pain was mostly intermittent and not progressive. Mechanical injury to the intercostal nerve during surgery appears to be the primary cause of this pain syndrome. ${ }^{16}$ However, Katz et al. linked the high intensity of early post-thoracotomy pain with the increased occurrence of persistent post-thoracotomy pain. ${ }^{9}$ This suggests that aggressive pain therapy to suppress early post-thoracotomy pain could reduce the intensity and the occurrence of long-term postthoracotomy pain.

Recently, pre-emptive analgesia has been shown to be useful in preventing postoperative pain. This technique prevents central sensitization by blocking afferent $\mathrm{C}$-fibre inputs from the periphery. The clinical efficacy of pre-emptive analgesia has been reported for various operations. ${ }^{5,6}$ However, there is no clear conclusion regarding the effectiveness of pre-emptive analgesia because study conditions, such as surgery, drugs, doses, administration routes, treatment duration and pain assessment methods, vary widely among studies. Kissin reported that noxious stimuli of low intensity may not produce a difference between preemptive analgesia and control groups, and that such stimuli may be too mild to evoke a sensitized state. ${ }^{7}$ Thoracotomy produces high intensely noxious stimuli sufficient to produce central sensitization., ${ }^{9,12,16,17}$ 
Further, the area of post-thoracotomy pain is restricted to the site of surgery, although shoulder or back pain that may be induced by patient position during surgery is not rare in thoracic surgery with lateral position. Accordingly, pre-emptive analgesia with epidural local anesthetics given in thoracic surgery should be more effective than in abdominal surgery, where such discrete pain localization is less likely. Previous studies comparing the effects of preoperative and postoperative epidural block in abdominal surgery failed to demonstrate any difference between groups in postoperative pain score or morphine requirement. ${ }^{18,19}$ In contrast, we found pre-emptive analgesia by epidural block with local anesthetic to be useful in managing post-thoracotomy pain in the early postoperative periods. The effect of pre-emptive analgesia against longterm postoperative pain and neuropathic pain has not been fully examined. Gottschalk et al. described preemptive epidural block with local anesthetic as being effective against long-term postoperative pain after prostatectomy. ${ }^{20}$ Bach et al. observed that lumbar epidural block with bupivacaine and morphine for 72 $\mathrm{hr}$ prior to amputation reduced the incidence of phantom limb pain. ${ }^{21}$ However, there are no previous reports describing the effect of pre-emptive epidural block against long-term postoperative pain with neuropathic characteristics.

A single pre-incision administration of epidural block may be insufficient to reduce postoperative pain. Cafferent fibre activity can be generated not only during surgery, but also in the early postoperative period as a result of persistent inflammation and hyperalgesia at the wound site. This activity may be sufficient to produce central sensitization. Thus, to prevent postoperative pain, epidural block should be initiated before the surgical incision and continued during and after surgery. ${ }^{22}$ In the present study, patients in the Pre group received a continuous epidural block with local anesthetic from 20 min before the surgical incision to $72 \mathrm{hr}$ after surgery, interrupting $\mathrm{C}$-afferent fibre input arising from the surgical incision and the postoperative local inflammation.

It has been suggested that administration of opioids as premedication or during induction and maintenance of anesthesia may prevent the development of central sensitization and attenuate the hypersensitivity if a sufficient dose of opioids is administered postoperatively. ${ }^{7,23-25}$ Aguilar et al. found no beneficial effect of pre-emptive thoracic epidural analgesia after thoracotomy. ${ }^{26}$ However, in their study, opioids were administered during anesthesia and postoperative period in both control and pre-emptive groups. The action of opioids possibly masked the effects of a single dose of local anesthetic administered before incision. In the present study we used an NSAID, indomethacin, as a postoperative supplementary analgesic. Pavy et al. showed that administration of rectal indomethacin to patients after thoracotomy caused a reduction in the VAS scores and in opioid requirements. ${ }^{27}$ Indomethacin acts by preventing prostaglandin synthesis at the wound site, with only negligible central action. It is not likely that postoperative indomethacin confounded the preemptive effect of epidural local anesthetics. The indomethacin dose we used was lower than in the previous study, simply because of the smaller body size of our patients.

In the present study, the VAS scores at four hours after surgery were moderately high in both groups. Central sensitization might be induced not only in the Post group but also in the Pre group, although the degree of sensitization might be different. It is possible that insufficient analgesia in the control group during the operation was directly related to the differences in pain conditions between the two groups in the early and late postoperative period. Further studies with adequate analgesia during the operation and early postoperative period will be necessary to evaluate the effect of pre-emptive analgesia on long-term postthoracotomy pain. Moreover, combinations of local anaesthetics, opioids, NSAIDs, and ketamine, an NMDA antagonist, ${ }^{28}$ should be examined to determine the optimal regimen for the prevention of postoperative neuropathic pain. In addition, other methods of pain assessment, such as VAS with motion, multidimensional pain scale, may be useful to evaluate pain intensities of the patients precisely. We were unable to assess the VAS with motion, because some patients were reluctant to move in the early postoperative period.

In summary, perioperative continuous epidural block with local anesthesia reduced the intensity and incidence of long-term post-thoracotomy pain. Pain therapy initiated before surgical incision is useful to reduce the long-lasting postoperative pain with neuropathic character.

\section{Appendix}

1. Do you currently have pain in your chest incision?

2. How great is your severest pain compared with the worst pain imaginable? Please choose an appropriate number along the line below.

no pain

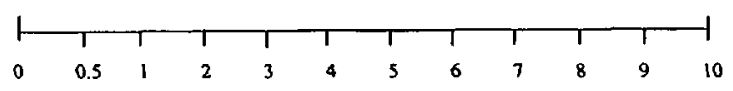


3. What kind of pain do you have?

Intermittent

Continuous

Aching

Numbness

Tenderness

Burning

Others

4. Do you have an area of sensation loss on the side of your incision?

5. Is your pain interfering with your life?

6. Are you now taking medications for your pain?

\section{References}

1 Woolf $\mathrm{CJ}$. Evidence for a central component of postinjury pain hypersensitivity. Nature 1983; 306: 686-8.

2 Woolf CJ. Recent advances in the pathophysiology of acute pain. Br J Anaesth 1989; 63: 139-46.

3 Dickenson AH, Sullivan AF. Subcutaneous formalininduced activity of dorsal horn neurones in the rat: differential response to an intrathecal opiate administerd pre or post formalin. Pain 1987; 30: 349-60.

4 Tashpal K, Katz J, Coderre TJ. Effects of preemptive or postinjury intrathecal local anesthesia on persistent nociceptive responses in rats. Anesthesiology 1996; 84: 1119-28.

5 Woolf CJ, Chong M-S. Preemptive analgesia - treating postoperative pain by preventing the establishment of central sensitization. Anesth Analg 1993; 77: 362-79.

$6 \mathrm{Dabl} J B, \mathrm{Keblet} H$. The value of pre-emptive analgesia in the treatment of postoperative pain. $\mathrm{Br} \mathrm{J}$ Anaesth 1993; 70: 434-9.

7 Kissin I. Preemptive analgesia. Why its effect is not always obvious (Editorial). Anesthesiology 1996; 84: 1015-9.

8 Dajczman E, Gordon A, Kreisman H, Wolkove N. Longterm postthoracotomy pain. Chest 1991; 99: 270-4.

9 Katz J, Jackson M, Kavanagh BP, Sandler AN. Acute pain after thoracic surgery predicts long-term post-thoracotomy pain. Clin J Pain 1996; 12: 50-5.

10 Conacher ID. Pain relief after thoracotomy. $\mathrm{Br} \mathrm{J}$ Anaesth 1990; 65: 806-12.

11 Kavanagh BP, Katz J, Sandler AN. Pain control after thoracic surgery. A review of current techniques. Anesthesiology 1994; 81: 737-59.

12 Katz J, Kavanagh BP, Sandler AN, et al. Preemptive analgesia. Clinical evidence of neuroplasticity contributing to postoperative pain. Anesthesiology 1992; 77: 439-46.

13 Kalso E, Perttunen K, Kaasinen S. Pain after thoracic surgery. Acta Anaesthesiol Scand 1992; 36: 96-100.

14 Matsunaga M, Dan K, Manabe FY, Hara F. Residual pain of $\mathbf{9 0}$ thoracotomy patients with malignancy and non-malignancy. Pain 1990; (Supp15): S148.

15 Benedetti $F$, Vighetti S, Amanzio $M$, et al. Dose-response relationship of opioids in nociceptive and neuropathic postoperative pain. Pain 1998; 74: 205-11.

16 Benedetti F, Amanzio M, Casadio C, et al. Postoperative pain and surperficial abdominal reflexes after posterolateral thoracotomy. Ann Thorac Surg 1997; 64: 207-10.

17 Loan WB, Morrison JD. The incidence and severity of postoperative pain. $\mathrm{Br}$ J Anaesth 1967; 39: 695-8.

18 Dabl JB, Hansen BL, Hjortsø NC, Erichsen CJ, Møiniche S, Kehlet $H$. Influence of timing on the effect of continuous extradural analgesia with bupivacaine and morphine after major abdominal surgery. $\mathrm{Br} \mathrm{J}$ Anaesth 1992; 69: 4-8.

19 Pryle BJ, Vanner RG, Enriquez N, Reynolds F. Can preemptive lumbar epidural blockade reduce postoperative pain following abdominal surgery? Anaesthesia 1993; 48: $120-3$.

20 Gottschalk A, Smith DS, Jobes DR, et al. Preemptive epidural analgesia and recovery from radical prostatectomy. A randomized controlled trial. JAMA 1998; 279: 1076-82.

21 Bach $S$, Noreng MF, Tjéllden NU. Phantom limb pain in amputees during the first $\mathbf{1 2}$ months following limb amputation, after preoperative lumbar epidural blockade. Pain 1988; 33: 297-301.

22 Moote $C$. Techniques for post-op pain management in the adult. Can J Anaesth 1993; 40: R19-24.

23 Katz J, Kavanagh BP, Sandler AN. Effect of preoperative opioid administration on postoperative pain (Letter). Br J Anaesth 1992; 69: 424.

24 Dierking GW, Dabl JB, Kanstrup J, Dabl A, Keblet $H$. Effect of pre-vs postoperative inguinal field block on postoperative pain after herniorraphy. $\mathrm{Br} \mathrm{J}$ Anaesth 1992; 68: 344-8.

25 Cатu $F$, Debucquoy $F$. Alfentanil infusion for postoparative pain: a comparison of epidural and intravenous routes. Anesthesiology 1991; 75: 171-8.

26. Aguilar JL, Rincón R, Domingo V, Espachs P, Preciado $M$ J, Vidal F. Absence of an early pre-cmptive effect after thoracic extradural bupivacaine in thoracic surgery. $\mathrm{Br} J$ Anaesth. 1996; 76: 72-6.

27 Papy T, Medley C, Murphy DF. Effect of indomethacin on pain relief after thoracotomy. $\mathrm{Br} J$ Anaesth 1990; 65: 624-7.

28 Tverskoy $M, O z$ Y, Isakson $A$, Finger J, Bradley EL Jr, Kissin I. Preemptive effect of fentanyl and ketamine on postoperative pain and wound hyperalgesia. Anesth Analg 1994; 78: 205-9. 